M L Bots

Associate Professor of Epidemiology

\section{THE EUROSTROKE PROJECT}

Stroke is the third leading cause of death in the Western societies. In addition, stroke is a major cause for morbidity and loss of quality of life.

For the United States estimates indicate more than 700000 incident strokes each year and 4.4 million stroke survivors. ${ }^{1}$ This also reflects the enormous economic burden on society. Despite developments in treatment of patients with symptoms of acute cerebrovascular disease, the best approach to reducing the burden of stroke on a population level remains prevention.

Preventive actions should be directed at those risk factors that are modifiable or potentially modifiable. ${ }^{2}$ Established modifiable risk factors are hypertension, smoking, diabetes mellitus, carotid stenosis, hyperlipidaemia, and atrial fibrillation. For these risk factors evidence is

\section{This issue live} and online www.jech.com present to indicate that modification is associated with a reduction in stroke risk. The evidence with respect to obesity, physical activity, alcohol consumption, homocysteine, hypercoagulability, hormone replacement therapy, and inflammation is less convincing. ${ }^{2}$

This issue of JECH comprises a number of papers based on the EUROSTROKE project. The EUROSTROKE database is drawn from a number of European population-based prospective follow up studies (cohorts) and is designed as a case-control study nested within these ongoing studies. The main objective is to investigate (1) the variation in incidence of fatal and non-fatal ischaemic and haemorrhagic stroke among populations in different European countries; (2) whether the observed differences in stroke incidence across countries can be explained by differences in prevalence of established cardiovascular risk factors; (3) the relative importance of selected dietary factors (potassium intake, smoking, alcohol consumption), haemostatic disturbances (fibrinogen) and comorbidity (rheumatic heart disease, atrial fibrillation) compared with established risk factors as determinants of the occurrence of ischaemic and haemorrhagic stroke. The results presented in this issue may provide supportive evidence for certain risk factors to be involved in the occurrence of stroke. Emphasis has been on a number of risk factors for which evidence is more limited, such fibrinogen, $\gamma$-glutamyltransferase, and left ventricular hypertrophy. In addition, analyses are presented in which the contribution of fibrinogen and ECG assessment in the prediction of stroke risk was evaluated relative to other easy obtainable risk factors.

1 American Heart Association. Stroke statistics. Dallas, TX: American Heart Association; 2000. Available at: http://www.americanheart.org/Heart_and_Stroke_A_Z_Guide/strokes.html. [Accessed September 2000.]

2 Goldstein LB, Adams R, Becker K, et al. Primary prevention of ischemic stroke: a statement for healthcare professionals from the Stroke Council of the American Heart Association. Circulation 2001; 103:163-82.

3 Grobbee DE, Koudstaal PJ, Bots ML, et al. Incidence and risk factors of ischaemic and haemorrhagic stroke in Europe. EUROSTROKE: A collaborative study among research centres in Europe: rationale and design. Neuroepidemiology 1996;15:291-300. 